\title{
Total vertex irregularity strength of comb product of two cycles
}

\author{
Rismawati Ramdani* and Muhammad Ali Ramdhani \\ UIN Sunan Gunung Djati Bandung, A.H. Nasution No 105 Bandung, Indonesia
}

\begin{abstract}
Let $G=(V(G), E(G))$ be a graph and $k$ be a positive integer. A total $k$-labeling of $G$ is a map $f: V(G) \cup$ $E(G) \rightarrow\{1,2 \cdots, k\}$. The vertex weight $v$ under the labeling $f$ is denoted by $w_{f}(v)$ and defined by $w_{f}(v)=f(v)+$ $\sum_{u v \in E(G)} f(u v)$. A total $k$-labeling of $G$ is called vertex irregular if there are no two vertices with the same weight. The total vertex irregularity strength of $G$, denoted by $\operatorname{tvs}(G)$, is the minimum $k$ such that $G$ has a vertex irregular total $k$-labeling. This labeling was introduced by Bača, Jendrol', Miller, and Ryan in 2007. Let $G$ and $H$ be two connected graphs. Let $o$ be a vertex of $H$. The comb product between $G$ and $H$, in the vertex $o$, denoted by $G \triangleright O$ $H$, is a graph obtained by taking one copy of $\mathrm{G}$ and $|V(G)|$ copies of $H$ and grafting the $i$-th copy of $H$ at the vertex $o$ to the $i$-th vertex of $G$. In this paper, we determine the total vertex irregularity strength of comb product of $C_{n}$ and $C_{m}$ where $m \in\{1,2\}$.
\end{abstract}

\section{Introduction}

Mathematics is a logical, analytical, and systematic thinking framework in helping human to solve their problems. One of the topics in mathematics that is interesting to study is graph labeling. One of the applications of graph labeling are to solve network problem.

In this paper, we discuss a kind of graph labeling, which is total vertex irregular labeling.

Let $G=(V, E)$ be a graph and $k$ be a positive integer. A total $k$-labeling of $G$ is a map $f: V(G) \cup E(G) \rightarrow\{1,2, \cdots, k\}$.

In 2007, Bača et al. introduced total irregular labeling. [1]. There are two kinds of the total irregular labeling, which are an edge irregular total labeling and a vertex irregular total labeling.

Definition 1.1. [1] For an integer $k$, a total labeling $f: V \cup E \rightarrow\{1,2, \cdots k\}$ is called an edge irregular total $k$-labelling of $G$ if every two distinct edges $e=u v$ and $f=w x$ in $E$ satisfy $w_{f}(e) \neq w_{f}(f)$, where $w_{f}(e)=f(u)+f(e)+f(v)$.

The notation $w_{f}(e)$ is called by the weight of edge $e$ under the labeling $f$.

Definition 1.2. [1] The minimum $k$ for which a graph $G$ has an edge irregular total $k$-labeling, denoted by tes $(G)$, is called the total edge irregularity strength of $G$.

Bača et al [1] gave a lower bound and an upper bound on $\operatorname{tes}(G)$ for arbitrary graph $G$. The bounds is given by Theorem 2.1.

Theorem 1.1 [1] Let $G=(V, E)$ be a graph with vertex set $V$ and a non-empty edge set $E$. Then

$$
\left\lceil\frac{|E|+2}{3}\right\rceil \leq \operatorname{tes}(G) \leq|E| \text {. }
$$

In the same paper, they also gave the exact value of $\operatorname{tes}(G)$ for $G$ are paths, cycles, stars, complete graphs, wheels, and friendships. [1]

Ivančo and S. Jendrol' [2] posed a conjecture that for arbitrary graph $G \neq K_{5}$,

$$
\operatorname{tes}(G)=\max \left\{\left\lceil\mid \frac{|E(G)|+2}{3}\right\rceil,\left\lceil\frac{\Delta(G)+1}{2}\right\rceil\right\} .
$$

Ramdani, et al [3] gave an upper bound on the total edge irregularity strength of disjoint union of graphs as follows.

Theorem 1.2 [3] The total edge irregularity strength of disjoint union of graphs $G_{1}, G_{2}, \cdots, G_{m}, m \geq 2$, is

$$
\operatorname{tes}\left(\bigcup_{i=1}^{m} G_{i}\right) \leq \sum_{i=1}^{m} \operatorname{tes}\left(G_{i}\right)-\left\lfloor\frac{m-1}{2}\right\rfloor \text {. }
$$

In [4], Nurdin et al. determined the total edge irregular strength of the corona product of paths with some graphs.

Definition 1.3. [1] For an integer $k$, a total labelling $f: V \cup E \rightarrow\{1,2, \cdots k\}$ is called a vertex irregular total $k$-labelling of $G$ if every two distinct vertices $u$ and $v$ in $V$ satisfy $w_{f}(u) \neq w_{f}(v)$, where $w_{f}(u)=f(u)+\sum_{u z \in E} f(u z)$.

The notation $w_{f}(u)$ is called by the weight of vertex $u$ under the labeling $f$.

Definition 1.4. [1] The minimum $k$ for which a graph $G$ has a vertex irregular total $k$-labeling, denoted by $\operatorname{tvs}(G)$, is called the total vertex irregularity strength of G.

In [1], Bača et al determined a lower bound and an upper bound on the total vertex irregularity strength of arbitrary graph $G$ with $p$ vertices, $q$ edges, the minimum degree $\delta$, and the maximum degree $\Delta$, as follows. 


$$
\left\lceil\frac{p+\delta}{\Delta+1}\right\rceil \leq t v s(G) \leq p+\Delta-2 \delta+1 .
$$

In [5], Nurdin et al. determined another lower bound of $\operatorname{tvs}(G)$ for $G$ a connected graph as follows.

Theorem 1.3 [5] Let $G$ be a connected graph having $n_{i}$ vertices of degree $(i=\delta, \delta+1, \delta+2, \cdots, \Delta)$, where $\delta$ and $\Delta$ are the minimum and the maximum degree of $G$, respectively. Then

$$
\operatorname{tvs}(G) \geq \max \left\{\left\lceil\frac{\delta+n_{\delta}}{\delta+1}\right],\left\lceil\frac{\delta+n_{\delta}+n_{\delta+1}}{\delta+2}\right\rceil, \cdots,\left\lceil\frac{\delta+\sum_{i=\delta}^{\Delta} n_{i}}{\Delta+1}\right\rceil\right\} .
$$

Ramdani et al., in [6], determined an upper bound on the total vertex irregularity strength of Cartesian product of $P_{2}$ and arbitrary regular graph $G$.

Theorem 1.4 [6]. Let $G$ be an $r$-regular graph for $r \geq$ 1. Then

$$
\operatorname{tvs}\left(P_{2} \square G\right) \leq 2 \operatorname{tvs}(G) .
$$

In [7] and [8], Ramdani et al. determined an exact value of $\operatorname{tvs}(G)$ for $G$ are ladders and books. Nurdin et al. [9] gave the exact values of the total vertex irregularity strength for several types of trees and disjoint union of paths. Przybylo, in [10], gave a linear bound on $\operatorname{tvs}(G)$.

Combining edge and vertex irregular total labeling, Marzuki et al., in [11], introduced new irregular labeling, namely totally irregular total labeling, defined as follows.

Definition 1.5 [11] For an integer $k$, a total labelling $f: V \cup E \rightarrow\{1,2, \cdots k\}$ is called a totally irregular total $k$-labelling of $G$ if every two distinct edges $e=u v$ and $f=w x$ in $E$ satisfy $w_{f}(e) \neq w_{f}(f)$ and every two distinct vertices $u$ and $v$ in $V$ satisfy $w_{f}(u) \neq w_{f}(v)$, where $w_{f}(e)=f(u)+f(e)+f(v)$ and $w_{f}(u)=f(u)+\sum_{u z \in E} f(u z)$.

Definition 1.6. [11] The minimum $k$ for which a graph $G$ has a totally irregular total $k$-labelling, denoted by ts $(G)$, is called the total irregularity strength of $G$.

In the same paper, Marzuki gave a lower bound on $\operatorname{ts}(G)$ that

$$
t s(G) \geq \max \{\operatorname{tes}(G), \operatorname{tvs}(G)\} .
$$

An upper bound on ts $(\mathrm{G})$ was given by Ramdani et al. in [12] as follows.

Theorem 1.5 [12] Let $G$ be a graph of order $p$. Let the sequence $F_{n}$ of Fibonacci numbers be defined by the recurrence relation $F_{n}=F_{n-1}+F_{n-2}, n \geq 3$, with seed values $F_{1}=1$ and $F_{2}=2$. Then the total irregularity strength of a graph $G$ is

$$
t s(G) \leq F_{p} .
$$

In the same paper, [12], Ramdani et al. determined the exact value of $t s(G)$ for $G$ are gears, fungus, and $m$ copies of stars.

Other results about $t s(G)$ were given by Ramdani et al in [13]. In the paper, they gave the exact value of $t s(G)$ for $G$ are Cartesian product of $P_{2}$ and some families of graphs. In [14], Ramdani et al. gave the total irregularity strength of freindship.
In [15], Ramdani et al. determined the total irregularity strength of regular graphs. In the paper, they gave an upper bound on total irregularity strength of $m$ copies of arbitrary graph $G$. Also they gave the exact value of the total irregularity strength of $m$ copies of path $P_{2}$.

In this paper, we determine the exact value of the total vertex irregularity strength of comb product of two cycles. The definition of comb product graph is given below.

Definition 1.7 Let $G$ and $H$ be two connected graphs. Let $o$ be a vertex of $H$. The comb product between $G$ and $H$, in the vertex $o$, denoted by $G \triangleright_{o} H$, is a graph obtained by taking one copy of $\mathrm{G}$ and $|V(G)|$ copies of $H$ and grafting the $i$-th copy of $H$ at the vertex $o$ to the $i$-th vertex of $G$.

\section{Main Results}

In this paper, we give the exact value of the total vertex irregularity strength of $C_{n} \triangleright_{o} C_{4}$ and $C_{n} \triangleright_{o} C_{5}$. The first result is given by Theorem 2.1

Theorem 2.1 Let $C_{n}$ be a cycle with $n$ vertices and $C_{4}$ be a cycle with 4 vertices, then for $n \geq 3$,

$$
\operatorname{tvs}\left(C_{n} \triangleright_{o} C_{4}\right)=n+1 .
$$

Proof. Let the vertex set of $C_{n} \triangleright_{o} C_{4}$ be

$$
\left\{u_{i j} \mid 1 \leq i \leq n, 1 \leq j \leq 4\right\}
$$

and the edge set be

$$
\begin{array}{r}
\left\{u_{i 1} u_{i 2}, u_{i 2} u_{i 3}, u_{i 3} u_{i 4}, u_{i 4} u_{i 1} \mid 1 \leq i \leq n\right\} \\
\cup\left\{u_{i 1} u_{(i+1) 1} \mid 1 \leq i \leq n-1\right\} \cup\left\{u_{n 1} u_{i 1}\right\}
\end{array}
$$

The ilustration of graph $C_{n} \triangleright_{o} C_{4}$ can be seen in the Fig. 1.

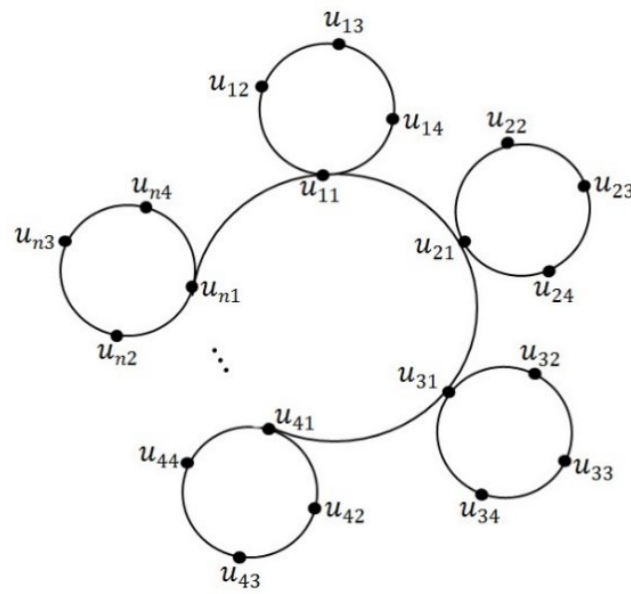

Fig. 1. A graph $C_{n} \triangleright_{o} C_{4}$

Graph $C_{n} \triangleright_{o} C_{4}$ has $3 n$ vertices with degree $\delta=2$ and $n$ vertices with degree $\Delta=4$. By using Theorem 1.3, we have

$$
\begin{aligned}
\operatorname{tvs}\left(C_{n} \triangleright o C_{4}\right) & \left.\geq \max \left\{\left[\frac{\delta+n_{\delta}}{\delta+1}\right], \mid \frac{\delta+n_{\delta}+n_{\delta+1}}{\delta+2}\right], \cdots,\left[\frac{\delta+\sum_{i=\delta}^{\Delta} n_{i}}{\Delta+1}\right]\right\} . \\
& \left.=\max \left\{\left[\frac{2+3 n}{2+1}\right], \mid \frac{2+3 n+n}{4+1}\right]\right\}
\end{aligned}
$$




$$
\begin{aligned}
& =\max \left\{\left\lceil\frac{2+3 n}{3}\right\rceil,\left\lceil\frac{4 n+2}{5}\right\rceil\right\} \\
& =\left\lceil\frac{2+3 n}{3}\right\rceil \\
& =n+1 .
\end{aligned}
$$

So that, we have

$$
\operatorname{tvs}\left(C_{n} \triangleright C_{4}\right) \geq n+1 \text {. }
$$

Define a labeling $f$ of $V\left(C_{n} \triangleright_{o} C_{4}\right) \cup E\left(C_{n} \triangleright_{o} C_{4}\right)$ as follows :

$$
\begin{gathered}
f\left(u_{i 1}\right)=n+1, \text { for } 1 \leq i \leq n ; \\
f\left(u_{i 2}\right)=f\left(u_{i 3}\right)=f\left(u_{i 4}\right)=i, \text { for } 1 \leq i \leq n ; \\
\left(u_{i 1} u_{i 2}\right)=f\left(u_{i 2} u_{i 3}\right)=i, \text { for } 1 \leq i \leq n ; \\
f\left(u_{i 3} u_{i 4}\right)=f\left(u_{i 4} u_{i 1}\right)=i+1, \text { for } 1 \leq i \leq n ; \\
f\left(u_{i 1} u_{(i+1) 1}\right)=n+1, \text { for } 1 \leq i \leq n-1 ; \\
f\left(u_{11} u_{n 1}\right)=n+1 .
\end{gathered}
$$

The labeling $f$ gives weight of each vertex, for $1 \leq i \leq n$, as follows :

$$
\begin{array}{rlc}
w_{f}\left(u_{i 1}\right)= & f\left(u_{i 1}\right)+f\left(u_{i 1} u_{i 2}\right)+f\left(u_{i 4} u_{i 1}\right) \\
& +f\left(u_{i 1} u_{(i+1) 1}\right)+f\left(u_{(i-1) 1} u_{i 1}\right) \\
& & (n+1)+(i)+(i+1) \\
= & +(n+1)+(n+1) \\
w_{f}\left(u_{i 2}\right)= & 3 n+4+2 i, \\
= & f\left(u_{i 2}\right)+f\left(u_{i 1} u_{i 2}\right)+f\left(u_{i 2} u_{i 3}\right) \\
= & (i)+(i)+(i) \\
w_{f}\left(u_{i 3}\right)= & 3 i \\
= & & (i)+(i)+(i+1) \\
= & & 3 i+1 \\
w_{f}\left(u_{i 4}\right)= & f\left(u_{i 4}\right)+f\left(u_{i 3} u_{i 4}\right)+f\left(u_{i 4} u_{i 1}\right) \\
= & (i)+(i+1)+(i+1) \\
= & & 3 i+2
\end{array}
$$

It can be seen that there are no two vertices of the same weight.

So, $f$ is a total vertex irregular labeling of $C_{n} \triangleright_{o} C_{4}$. The maximum label of the labeling $f$ is $n+1$. So, we have

$$
\operatorname{tvs}\left(C_{n} \triangleright_{o} C_{4}\right) \leq n+1 \text {. }
$$

From (18) and (29), we can conclude that for $n \geq 3$,

$$
\operatorname{tvs}\left(C_{n} \triangleright_{o} C_{4}\right)=n+1 .
$$

This paper also determine the total vertex irregularity strength of $C_{n} \triangleright_{o} C_{5}$. The result can be seen in the theorem below.

Theorem 2.2 Let $C_{n}$ be a cycle with $n$ vertices and $C_{5}$ be a cycle with 5 vertices. For $n \geq 3$,

$$
\operatorname{tvs}\left(C_{n} \triangleright_{o} C_{5}\right)=\left\lceil\frac{4 n+2}{3}\right\rceil
$$

Proof. Let the vertex set of $C_{n} \triangleright_{o} C_{5}$ be

$$
\left\{u_{i j} \mid 1 \leq i \leq n, 1 \leq j \leq 5\right\}
$$

and the edge set be

$$
\begin{aligned}
\left\{u_{i 1} u_{i 2},\right. & \left.u_{i 2} u_{i 3}, u_{i 3} u_{i 4}, u_{i 4} u_{i 5}, u_{i 5} u_{i 1} \mid 1 \leq i \leq n\right\} \\
& \cup\left\{u_{i 1} u_{(i+1) 1} \mid 1 \leq i \leq n-1\right\} \\
& \cup\left\{u_{n 1} u_{i 1}\right\}
\end{aligned}
$$

In the Fig. 2, we can see the ilustration of graph $C_{n} \triangleright_{o}$ $C_{5}$.

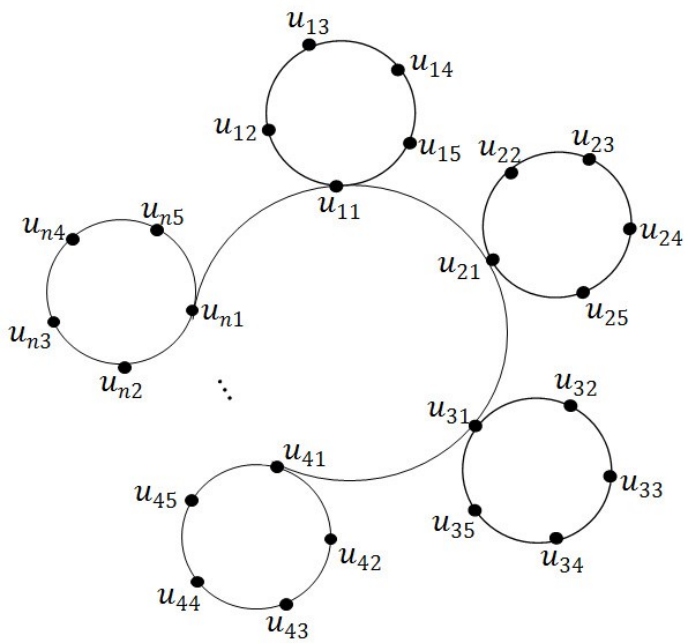

Fig. 2. A graph $C_{n} \triangleright_{o} C_{5}$

It can be seen in the Fig. 2. that graph $C_{n} \triangleright_{o} C_{5}$ has $4 n$ vertices with degree $\delta=2$ and $n$ vertices with degree $\Delta=4$. We use Theorem 2.3 to have

$$
\begin{aligned}
\operatorname{tvs}\left(C_{n} \triangleright o C_{5}\right) \geq & \max \left\{\left\lceil\frac{\delta+n_{\delta}}{\delta+1}\right\rceil,\left[\frac{\delta+n_{\delta}+n_{\delta+1}}{\delta+2}\right\rceil, \cdots,\left\lceil\frac{\delta+\sum_{i=\delta}^{\Delta} n_{i}}{\Delta+1}\right\rceil\right\} . \\
& =\max \left\{\left\lceil\frac{2+4 n}{2+1}\right\rceil,\left\lceil\frac{2+4 n+n}{4+1}\right\rceil\right\} \\
& =\max \left\{\left\lceil\frac{2+4 n}{3}\right\rceil,\left\lceil\frac{5 n+2}{5}\right\rceil\right\} \\
& =\left\lceil\frac{4 n+2}{3}\right\rceil
\end{aligned}
$$

So that, we have

$$
\operatorname{tvs}\left(C_{n} \triangleright C_{5}\right) \geq\left\lceil\frac{4 n+2}{3}\right\rceil .
$$

Next, define a labeling $f$ of $V\left(C_{n} \triangleright_{o} C_{5}\right) \cup E\left(C_{n} \triangleright_{o} C_{5}\right)$ as follows :

$$
\begin{aligned}
& f\left(u_{i 1}\right)=f\left(u_{i 5} u_{i 1}\right)=\left\lceil\frac{4 n+2}{3}\right\rceil, \text { for } 1 \leq i \leq n \\
& f\left(u_{i 2}\right)=\left\lceil\frac{4 i-3}{3}\right\rceil, \text { for } 1 \leq i \leq n \\
& f\left(u_{i 3}\right)=f\left(u_{i 1} u_{i 2}\right)=\left\lceil\frac{4 i-2}{3}\right\rceil, \text { for } 1 \leq i \leq n \\
& f\left(u_{i 4}\right)=f\left(u_{i 2} u_{i 3}\right)=\left\lceil\frac{4 i-1}{3}\right\rceil, \text { for } 1 \leq i \leq n \\
& f\left(u_{i 5}\right)=f\left(u_{i 3} u_{i 4}\right)=\left\lceil\frac{4 i}{3}\right\rceil, \text { for } 1 \leq i \leq n
\end{aligned}
$$




$$
\begin{aligned}
& f\left(u_{i 4} u_{i 5}\right)=\left\lceil\frac{4 n+1}{3}\right\rceil, \text { for } 1 \leq i \leq n \\
& f\left(u_{i 1} u_{(i+1) 1}\right)=\left\lceil\frac{4 n+2}{3}\right\rceil, \text { for } 1 \leq i \leq n-1 ; \\
& f\left(u_{11} u_{n 1}\right)=\left\lceil\frac{4 n+2}{3}\right\rceil .
\end{aligned}
$$

The weight of vertices of $C_{n} \triangleright_{o} C_{5}$ under labeling $f$ vertex, as follows :

For $1 \leq i \leq n$,

$$
\begin{aligned}
& w_{f}\left(u_{i 1}\right)=3\left\lceil\frac{4 n+2}{3}\right\rceil+\left\lceil\frac{4 i-2}{3}\right\rceil+\left\lceil\frac{4 i+2}{3}\right\rceil, \\
& w_{f}\left(u_{i 2}\right)=4 i-1, \\
& w_{f}\left(u_{i 3}\right)=4 i \\
& w_{f}\left(u_{i 4}\right)=4 i+1, \text { and } \\
& w_{f}\left(u_{i 5}\right)=4 i+2 .
\end{aligned}
$$

It can be seen that there are no two vertices of $C_{n} \triangleright_{o}$ $C_{5}$ under labeling $f$ of the same weight.

So that, $f$ is a total vertex irregular labeling of $C_{n} \triangleright_{o}$ 5. The maximum label of labeling $f$ is $\left[\frac{4 n+2}{3}\right]$. So, we have

$$
\operatorname{tvs}\left(C_{n} \triangleright_{o} C_{5}\right) \leq\left\lceil\frac{4 n+2}{3}\right\rceil
$$

From (40) and (54), we conclude that

$$
\operatorname{tvs}\left(C_{n} \triangleright_{o} C_{4}\right)=n+1 \text {, }
$$

for $n \geq 3$.

\section{References}

1. M. Bača, S. Jendrol', M. Miller, and J. Ryan, On irregular total labellings. Discret. Math. 307, (2007), $1378-1388$

2. J. Ivančo and S. Jendrol', Total edge irregularity strength of trees. Discuss. Math. Graph Theory, 26, (2006), 449-456.

3. R. Ramdani, A.N.M. Salman, H. Assiyatun, A. Semaničová-Feňovcičová, and M. Bača, On the total irregularity strength of disjoint union of arbitrary graphs, Math. Reports, 18(68) 4, (2016), 469-482.

4. Nurdin, Salman, A.N.M., Baskoro, and E.T. The total edge-irregular strengths of the corona product of paths with some graphs. J. Comb. Math. Comb. Comput. 65, (2008), 163-175.

5. Nurdin, E.T. Baskoro, A.N.M. Salman, and N.N. Gaos, On the total vertex irregularity strength of trees, Discrete Math., 310, (2010), 3043 - 3048.

6. R. Ramdani, A.N.M. Salman, and H. Assiyatun, An upper bound on the total vertex irregularity strength of the Cartesian product of $P 2$ and an arbitrary regular graph, Procedia Computer Science, 74, (2015), 105111.
7. R. Ramdani, Pelabelan total vertex irregular pada graf tangga, Prosiding Konferensi Nasional Sains dan Aplikasinya, (2011), 349-356.

8. R. Ramdani, and H. Assiyatun, Total vertex irregularity strength dari graf buku, Jurnal Teori dan Terapan Matematika, 10(1), (2011), 1-14.

9. Nurdin, A.N.M. Salman, N.N. Gaos, and E.T. Baskoro, On the total vertex-irregular strength of a disjoint union of $t$ copies of a path. J. Combin. Math. Combin. Comput. 71, (2009), 227-233.

10. J. Przybylo, Linear bound on the irregularity strength and the total vertex irregularity strength of graphs, SIAM J. Discrete Math., 23, (2009), 511 - 516.

11. C.C. Marzuki, A.N.M. Salman, and M. Miller, On the total irregularity strength on cycles and paths, Far East Journal of Mathematical Sciences, 82(1), (2013) $1-21$.

12. R. Ramdani, A.N.M. Salman, H. Assiyatun, A. Semaničová-Feňovcičová, and M. Bača, Total irregularity strength of three families of graphs, Mathematics in Computer Science, 9(2), (2015), 229237.

13. R. Ramdani and A.N.M. Salman,: On the total irregularity strength of some Cartesian product graphs, AKCE Int. J. Graphs Comb., 10(2), (2013), 199-209.

14. R. Ramdani, A.N.M. Salman, and H. Assiyatun, On the total irregularity strength of friendship, Proceeding The 4th Basic Science International Conference in conjunction with The 5th International Conference on Global Resource Conversation, 10, (2014), 151-154.

15. R. Ramdani, A.N.M. Salman, and H. Assiyatun, On the total irregularity strength of regular graphs, Journal of Mathematical and Fundamental Sciences, 47(3), (2015), 281-295. 